\title{
Re-thinking treatment targets in child and adolescent psychiatry
}

\author{
Carmen Moreno ${ }^{1} \cdot$ Alessandro Zuddas $^{2,3}$
}

Published online: 28 February 2019

c) Springer-Verlag GmbH Germany, part of Springer Nature 2019

In 1970, Robins and Guze proposed five steps to achieve valid classification of mental disorders: clinical description, laboratory study, exclusion of other disorders, follow-up study, and family history [1]. Those steps helped establish significant validity (defined as a coherent syndrome clinicians can describe and measure) and reliability (meaning different clinicians agree on the same diagnosis) for specific psychiatric disorders, leading to consistent definitions of "natural" outcomes, specific responses to therapeutic interventions, and prognosis. Diagnoses in psychiatry are still based on clinical constructs defined by observation and patient's reports. The ways diagnoses are formulated influence the design of innovative treatments and not always for the better. Patients are usually included in clinical trials based on specific mental diagnoses and narrow enrolment standards to ensure homogeneous samples. That limits the applicability of findings in everyday practice because specific symptoms often overlap among psychiatric diagnoses, as do psychiatric and medical comorbidities, with significant impact on diagnostic formulation, prognosis and treatment choices.

Initiatives such as RDoC or ROAMER [2, 3] call for increasing clinical and biological research to develop innovative research-oriented diagnostic formulations based on dimensions of observable behaviour and associated neurobiological characteristics, rather than on specific diagnostic "categorical" entities. This approach may be particularly

Carmen Moreno

cmoreno@hggm.es

1 Child and Adolescent Psychiatry Department, Hospital General Universitario Gregorio Marañón, School of Medicine, Universidad Complutense (UCM), IiSGM, CIBERSAM, Madrid, Spain

2 Department of Biomedical Sciences, Section Neuroscience and Clinical Pharmacology, University of Cagliari, Cagliari, Italy

3 Child and Adolescent Neuropsychiatry, “A. Cao” Paediatric Hospital, "G. Brotzu" Hospital Trust, Via E. Jenner, 09121 Cagliari, Italy relevant in the case of child and adolescent psychiatry. In fact, with the significant exceptions of conditions such as attention deficit/hyperactivity disorder (ADHD) and autism spectrum disorders (ASD), in which the full clinical symptomatology usually appears in early years, the clinical description (and corresponding validity and reliability) of many mental disorders in children are adapted from the corresponding adulthood clinical presentations. Yet, in children and adolescents, the age-specific clinical presentations for these disorders frequently include a combination of nonspecific symptoms, leading to delays of diagnosis and treatment implementation, which in turn may increase clinical impairment and reduce patient wellness.

Highly impairing clinical presentations such as severe irritability and emotional lability frequently appear as unspecific symptoms of different developmental psychiatric disorders such as ADHD, oppositional defiant disorder (ODD), conduct disorder (CD)/disruptive behaviour disorder (DBD), intermittent explosive disorder (IED), disruptive mood dysregulation disorder (DMDD), or anxiety disorder (AD) and often also ASD. In fact, severe irritability is one of the most common reasons for referral to child and adolescent mental health services [4], and is associated with significant functional impairments and exceptionally poor long-term outcomes [5] as well as increased suicidality [6]. Those associations are independent of the specific categorical diagnosis, and there is a significant gap between their impact on clinical burden and the available therapies we can offer to our patients. The article by Wesselhoeft et al. [7] in this issue, using data from 3435 children aged 7-10 years from the Danish National Birth Cohort, provides evidence to support the importance of severe irritability in mental health. The authors studied dimensions and subtypes of oppositionality, and find that, among the dimensions emerging from a threefactor model (angry/irritable, argumentative behaviour, and vindictiveness), the angry/irritable dimension was associated with high emotional problems and disorders and fewer social skills or positive attributes. Among the four oppositional defiant disorders identified, those with a predominance of angry/irritable symptoms were characterized by comorbid 
psychopathology, increased functional impairment and psychosocial problems. The study suggests that irritability is a clinical characteristic modulating presentation and prognosis and, therefore, a potential treatment target.

Irritability has been defined as an increased predisposition to anger compared with peers at the same developmental level including both behavioural and mood dysregulation components [8]. Irritability rises during normal early childhood development, peaking in preschool years, and declines thereafter, with another increase in adolescence. Self-regulation of irritable mood and behaviour occurs thanks to the development of cortical structures mediating emotion regulation and early executive function capability [9]. Emotion regulation plays a central role for the modulation of irritability, although there are few studies of the normative use of emotion regulation strategies over age. The few available data suggest that, compared to childhood, adolescence is a crucial developmental period characterized by a maladaptive shift in the use of emotion regulation, with an increase in the use of maladaptive strategies in detriment to the adaptive ones [10]. From a neuroscientific perspective, irritability has been defined as an "aberrant responding to frustrative non-reward and threat" referring to the emotional state characterized by the abnormal increase in activity and aggression when an objective cannot be fulfilled [11]. Frustrative non-reward is included under the negative valence system of the RDoC matrix. Biological underpinnings of these deficits include decreased activation of striatal and frontal regions in response to frustrative non-reward and altered amygdala response modulation in response to threat [11]. These alterations underlying emotional and behavioural dysregulation linked to irritability also affect the cardiac-respiratory output via the autonomic nervous system [12].

The most used scale to measure paediatric irritability in clinical trials, the ABC-C, is a questionnaire for caregivers assessing irritability in intellectual and developmental disabilities. These characteristics limit translation of findings to clinical populations without cognitive impairment and to adolescents, for whom patient report of symptoms is preferred. New instruments targeting irritability, such as the Affective Reactivity Index (ARI) and youth- and parent-reported versions, have shown promising results for assessing irritability in research settings [13]. A clinicianrated version of this instrument (CL-ARI) has also shown good psychometric properties for assessing behavioural and mood components of irritability across diagnostic groups [14], which makes it a good candidate for use in clinical trials. The emotional, behavioural and autonomic dysregulation (EBAD) linked to irritability, which can be empirically measured, would also be a relevant target for treatment outcome and stratification [12].

In the case of DMDD, stimulants, atypical antipsychotics and serotonergic antidepressants have been tested, although data are still too scarce to guide treatment recommendations [15]. There is also some evidence that in particular disorders some other medications may be of help, such as stimulants for irritable dysregulated children with ADHD or ODD/CD [16]. However, in regular psychiatric practice, second generation antipsychotics are the more common treatments for children with severe irritability regardless of the respective mental disorder [17]. The wide use of these medications is not supported by clinical trials, carries potential for adverse events, and there is no specific information available on appropriate doses, treatment duration or expected outcomes.

Given the high prevalence of irritability in paediatric clinical settings, its associated clinical burden, and the frequent co-occurrence across diagnoses, a pragmatic symptom-based approach could be appropriate for the study of specific interventions for irritability and for designing transdiagnostic trials towards this end. These trials should consider including sensitive developmental periods, such as adolescent years, using validated treatment outcome measures, and allow sufficient follow-up to provide information on the clinical utility of medication approaches. It is still too common for clinicians to use a personal trial-and-error approach without the support of evidence-based information. New innovative treatment approaches for developmental psychiatry should be designed to answer these relevant clinical questions.

Acknowledgements Supported by the Spanish Ministry of Science, Innovation and Universities. Instituto de Salud Carlos III (PI 14/02069, PI17/02227), co-financed by ERDF Funds from the European Commission, "A way of making Europe", CIBERSAM. Madrid Regional Government (B2017/BMD-3740 AGES-CM-2), European Union Structural Funds and European Union Seventh Framework Program and H2020 Program; Fundación Familia Alonso, Fundación Alicia Koplowitz and Fundación Mutua Madrileña.

\section{Compliance with ethical standards}

Conflicts of Interest $C$ Moreno reports grants from European Union Funds, Instituto de Salud Carlos III Spanish Ministry of Economy and Competitiveness, and declares honoraria for participating in Advisory boards or Data Safety Monitory Boards from Janssen, Servier, Nuvelution, Otsuka and Lundbeck. A Zuddas reports grants from European Union Funds and the Sardinian Regional Government, and declares honoraria for participating in Advisory boards or Data Safety Monitory Boards from Angelini, Otsuka, Lundbeck, Takeda, and EduPharma; royalties from Oxford University Press and Giunti OS; and research grants (clinical trials) from Angelini, Janssen, Lundbeck, Otsuka, Roche and Vifor.

\section{References}

1. Robins E, Guze SB (1970) Establishment of diagnostic validity in psychiatric illness: its application to schizophrenia. Am J Psychiatry 126(7):983-987 
2. Ip KI, Jester JM, Sameroff A, Olson SL (2019) Linking research domain criteria (RDoC) constructs to developmental psychopathology: the role of self-regulation and emotion knowledge in the development of internalizing and externalizing growth trajectories from ages 3-10. Dev Psychopathol 5:1-18. https://doi. org/10.1017/s0954579418001323 [Epub ahead of print]

3. Wittchen HU, Knappe S, Andersson G, Araya R, Banos Rivera RM, Barkham M, Bech P, Beckers T, Berger T, Berking M, Berrocal C, Botella C, Carlbring P, Chouinard G, Colom F, Csillag C, Cujipers P, David D, Emmelkamp PM, Essau CA, Fava GA, Goschke T, Hermans D, Hofmann SG, Lutz W, Muris P, Ollendick TH, Raes F, Rief W, Riper H, Tossani E, van der Oord S, Vervliet B, Haro JM, Schumann G (2014) The need for a behavioural science focus in research on mental health and mental disorders. Int J Methods Psychiatr Res 23(Suppl 1):28-40. https:// doi.org/10.1002/mpr.1409

4. Carlson GA, Potegal M, Margulies D, Gutkovich Z, Basile J (2009) Rages - what are they and who has them? J Child Adolesc Psychopharmacol 19(3):281-288. https://doi.org/10.1089/ cap. 2008.0108

5. Mulraney MA (2014) Irritability: an investigation of prevalence and clinical correlates in adolescence and adulthood. PhD Thesis, Monash University, Melbourne. https://au-east.erc.monash.edu. au/fpfiles/7641625/monash_128325.pdf

6. Pickles A, Aglan A, Collishaw S, Messer J, Rutter M, Maughan B (2010) Predictors of suicidality across the life span: the Isle of Wight study. Psychol Med 40(9):1453-1466. https://doi. org/10.1017/S0033291709991905

7. Wesselhoeft R, Stringaris A, Sibbersen C, Kristensen RV, Bojesen AB, Talati A (2019) Dimensions and subtypes of oppositionality and their relation to comorbidity and psychosocial characteristics. Eur Child Adolesc Psychiatry. https://doi.org/10.1007/s0078 7-018-1199-8

8. Brotman MA, Kircanski K, Stringaris A, Pine DS, Leibenluft E (2017) Irritability in youths: a translational model. Am J Psychiatry 174(6):520-532. https://doi.org/10.1176/appi.ajp.2016.16070 839

9. Wakschlag LS, Perlman SB, Blair RJ, Leibenluft E, BriggsGowan MJ, Pine DS (2018) The neurodevelopmental basis of early childhood disruptive behavior: irritable and callous phenotypes as exemplars. Am J Psychiatry 175(2):114-130. https://doi. org/10.1176/appi.ajp.2017.17010045

10. Cracco E, Goossens L, Braet C (2017) Emotion regulation across childhood and adolescence: evidence for a maladaptive shift in adolescence. Eur Child Adolesc Psychiatry 26(8):909-921. https ://doi.org/10.1007/s00787-017-0952-8

11. Stringaris A, Vidal-Ribas P, Brotman MA, Leibenluft E (2018) Practitioner Review: definition, recognition, and treatment challenges of irritability in young people. J Child Psychol Psychiatry 59(7):721-739. https://doi.org/10.1111/jcpp.12823

12. Singh J, Santosh P (2018) Key issues in Rett syndrome: emotional, behavioural and autonomic dysregulation (EBAD) - a target for clinical trials. Orphanet J Rare Dis 13(1):128. https://doi. org/10.1186/s13023-018-0873-8

13. Stringaris A, Goodman R, Ferdinando S, Razdan V, Muhrer E, Leibenluft E, Brotman MA (2012) The affective reactivity index: a concise irritability scale for clinical and research settings. J Child Psychol Psychiatry 53(11):1109-1117. https://doi.org/10.111 1/j.1469-7610.2012.02561.x

14. Haller SP, Kircanski K, Stringaris A, Clayton M, Bui, Agorsor C, Sofia I. Cardenas SI, Towbin KE, Pine DS, Leibenluft E, Brotman MA (2019) The clinician affective reactivity index: validity and reliability of a clinician-rated assessment of irritability (submitted)

15. Benarous X, Consoli A, Guilé JM, Garny de La Rivière S, Cohen D, Olliac B (2017) Evidence-based treatments for youths with severely dysregulated mood: a qualitative systematic review of trials for SMD and DMDD. Eur Child Adolesc Psychiatry 26(1):523. https://doi.org/10.1007/s00787-016-0907-5

16. Balia C, Carucci S, Coghill D, Zuddas A (2018) The pharmacological treatment of aggression in children and adolescents with conduct disorder. Do callous-unemotional traits modulate the efficacy of medication? Neurosci Biobehav Rev 91:218-238

17. Nesvåg R, Hartz I, Bramness JG, Hjellvik V, Handal M, Skurtveit $S$ (2016) Mental disorder diagnoses among children and adolescents who use antipsychotic drugs. Eur Neuropsychopharmacol 26(9):1412-1418. https://doi.org/10.1016/j.euron euro.2016.07.001 